\title{
A CASE OF BRONCHOSPASM INDUCED BY SUCCINYLCHOLINE
}

\author{
Natalis Bele-Binda, M.D., and Franco Valerr, M.D.
}

Mrss P. Nz, AGE 18 years (record number 36468), was admitted to the Cliniques Universitaires Lovanium on 1 March 1966 for the treatment of back pain which was diagnosed as a thoracolumbar Pott's disease. The disorder involved the vertebral bodies of $\mathrm{D}-11, \mathrm{D}-12$ and $\mathrm{L}-1$.

There was no family history of consequence. The patient had previously had malaria.

On her admission, blood studies disclosed the presence of Plasmodia, along with a 24 per cent eosinophilia. On 15 April, a curettage and bone graft of the thoracolumbar tuberculous lesion was scheduled under general anaesthesia.

After a premedication including atropine $0.5 \mathrm{mg}$ and pethidine $50 \mathrm{mg}$, anaesthesia was induced with thiopentone $200 \mathrm{mg}$, followed by succinylcholine $100 \mathrm{mg}$. As soon as the myorelaxant was injected, the patient went into a severe bronchospasm. She was ventilated with pure oxygen. Endotracheal intubation proved difficult, and was only achieved after a further intravenous dose of $50 \mathrm{mg}$ succinylcholine. The bronchospastic state vanished after the administration of aminophylline $250 \mathrm{mg}$ and dexamethasone $4 \mathrm{mg}$. It was decided that the operation should be postponed.

On 19 April, the patient was again brought to the operating room for surgical correction of her Pott's disease. This time her premedication included an aminophylline suppository along with pethidine and atropine. In order to exclude the use of thiopentone for the induction of anaesthesia, narcosis was obtained with Thalamonal (Innovar). Then, $100 \mathrm{mg}$ of succinylcholine was injected intravenously, and very soon after this, the same bronchospastic crisis reoccurred. This was successfully controlled with the intravenous use of aminophylline $250 \mathrm{mg}$ and dexamethasone $4 \mathrm{mg}$.

\section{Comments}

The occurrence of a severe bronchospasm twice in the same patient following the injection of succinylcholine prompted us to hold this drug responsible for this dramatic increase in the bronchomotor tone, either as the causative agent or as a trigger factor. Our thesis was supported by the fact that we scrutinized in vain both the personal and familial allergic antecedents of our patient. We found positively no asthma. The high eosinophil count ( 24 per cent) noticed on the blood smear was traced to the presence of Plasmodia.

Among the myorelaxants, d-Tubocurarine, gallamine and succinylcholine (Suxamethonium) can release various amounts of histamine. Curare is the most power-

From the Department of Anesthesiology, Cliniques Universitaires Lovanium, Kinshasa, Congolese Democratic Republic. 
ful of these to increase the plasma histamine level. ${ }^{2}$ Suxamethonium releases no more than 1 to 2 per cent of the histamine that can be poured out by d-Tubocurarine. The histamine which is released acts on the effector end-organs localised in the bronchial wall, leading to bronchoconstriction and sometimes to full-blown spasm.

Experiments in the dog demonstrated that succinylcholine can induce a bronchospastic state $;^{1}$ however, during clinical anaesthesia in man, ${ }^{2-6}$ this drug is known to induce bronchospasm very infrequently. The first case of a bronchospasm induced by succinylcholine was reported by Fellini and his co-workers in $1963 .{ }^{6}$

\section{SUMMARY}

We have reported a case of severe bronchospasm induced by succinylcholine in an eighteen-year-old patient devoid of asthmatic antecedents.

Our review of the literature on this subject leads us to conclude that such an occurrence is very infrequent in the practice of anaesthesia.

\section{REFERENCES}

1. Hummell, P. R. The effect of succinylcholine chloride on histamine induced bronchospasme in dogs. Anesth. analg. (Cleve) 37: 130-134 (1958).

2. Klaus Graf, GunNar Ström; \& Ake Wàhlin. Circulatory effects of succinylcholine in man. Acta anesth. Scand. Supplementum xIv.

3. Cecconnello, D.; Fanchiotti; \& Giussani Hexafluorenium-succinylcholcine in general anesthesia. Acta anesth. Scand. 12: 31-44 (1968).

4. Davidson, Churchill. A Practice of Anaesthesia, Second Edition (1966).

5. SAlEM, M. R.; KIM, Y.; \& ETR, E. L. Histamine Release Following intravenous injection of D. Tubocurarine. Anesthesiology. 29: 380-382 (1969).

6. Fellini, A. A.; Bernstein, R. L.; \& Zauder, H. L. Bronchospasm due to suxamethenium Brit. J. Anaest. 35, 657 (1963). 